\title{
Perceptions and Attitudes of Men towards their Wives' Menopausal Transition Period
}

\author{
Hanan J. Alzein ${ }^{1}$, Samira Habashneh ${ }^{1}$, Husam Al Khatib ${ }^{1}$, Rabia S. Allari ${ }^{1}$ \\ ${ }^{1}$ Faculty of Nursing, Al-Ahliyya Amman University, AlSult, Jordan
}

\begin{abstract}
Background: Menopause is a natural process that occurs in women's life as a part of normal aging. Recognition of women's needs during menopause is considered important and required to maintain good quality of life.
\end{abstract}

Objective: This study aims at exploring the perceptions and attitudes of men towards their wives during menopause in Jordan.

Method: This study used the descriptive approach. 104 men were randomly chosen, for data collection, the Attitude towards Menopause was adopted in this study.

Results: Study results concluded that the men's perceptions and attitudes toward their wives experiencing menopause in Jordan, ranged from (1.83-1.30), where the whole dimension scored a total mean of (1.55), which is of a medium level. The study also concluded that there is no relationship at level of $(0.05)$ between men's perceptions and attitudes toward their wives experiencing menopause in Jordan and age, nationality, educational level and marry year. And the results showed that there are no statistically significant differences in the men's perceptions and attitudes according to the age, and nationality in Jordan. While, there are statistically significant differences in theirperceptions and attitudes with the Marry year in favor of 1-10-year category.

Conclusion: Advising men to engage in various activities with his wife during menopause can positively affect their attitudes, improve their body image.

Keywords: Attitudes of men, Experience, Menopause, Perceptions, Transition period, Wives.

\section{Introduction}

Menopause is a natural process that occurs in women's life as a part of normal aging. The average age of menopause is between 51 and 52 years, and most of women live about one third of their life after menopause $^{[1]}$. And the majority may experience hot flushes and night sweating. For some women, the

\section{Corresponding Author:}

Rabia S. Allari

Al-Ahliyya Amman University, Faculty of Nursing, AlSult, Jordan

Mobile: 00962778474473

e-mail: r.allari@ammanu.edu.jo climacteric symptoms are troublesome, therefore a varying percentage of women look for medical advice due to symptoms related to the menopausal transition period.

It is a challenging duty for health care providers to improve management of menopausal women ${ }^{2[}$. Hormone therapy has been considered as a safe and well-established treatment of menopausal symptoms ${ }^{3[}$. Since the 1960s, hormone therapy has been established as a treatment of menopausal women and has been used by women. The usage of hormone therapy has increased for around $7 \%$ in the 1980 samong 53 to 54 years old women to more than $40 \%$ in $2017^{[1]}$.

The increase of hormone therapy use was probably justified by the confidence in the results from several 
observational studies in 1980s and 2017s which reported beneficial effects of continuing hormone therapy use. Results from several large-scale randomized clinical trials published after 1998 did not find proof for those long-term benefits of hormone therapy, and these new results attracted attention from media, and hence appeared to have a major impact. The new resultsheaded to a dramatic change in the treatment guidelines, and in the use of hormone therapy among women $]^{4,5[\text {. }}$

Mental perception is a reflection of things or indicators or events that a person has already realized .It is a psychological and mental skill that can be acquired and learned. Perception can be further considered as an outcome of mental processing and a rational source that codes a person's brain in order to respond according to this programming process. The perception mechanism depends on retrieving past experiences of things, events, or manifestation $] 6[$.

Recognition of women's needs during menopause is considered important and required to maintain good quality of life. Studies looking at men's conception and perception toward menopause revealed that men form a critical source of support in helping their women to cope with menopausal changes and challenges ]7[. Understanding of men for the changes experienced by menopausal women fosters the development of a better emotional support for their wives that help to improve the quality of marital relations ${ }^{8[\text {. This study aims at }}$ exploring the perceptions and attitudes of men towards their wives during menopause in Jordan.

Literature Review: Revision of previous studies related to menopause highlighted that with increased age women in general are exposed to significant physiologic changes during menopausal period which reflected on social, psychological and emotional changes. Women spend nearly $1 / 3$ of their lives in menopause and the period after menopause due to prolonged life span. In this period, women live a lot of change in their family, work and social lives besides some roles and responsibilities as wife, mother, business woman, grandmother and friend $^{19[}$.

One study by Parish, et al. (2019) aimed to assess the men's awareness and their understanding of their partner's menopausal transition. Results showed that men are aware of their partner's menopausal transition and may influence decisions relating to symptom management such as, difficulty sleeping, and lack of
energy.Most men in the same study reported they were negatively impacted by the previous symptoms. They engaged in discussions with their wives regarding menopausal symptoms and believed they were influential in their wives decision to seek treatment ${ }^{10[\text {. }}$

Furthermore, Santoro, Epperson \& Mathews (2015) aimed in their study to identify menopause in both women and men, as well as the social, psychological and health consequences of menopause on women and men and how to face the negative effects of it. The study used the descriptive approach in which focus groups where employed. The researcher interviewed six groups of women at menopause stage to ask them about this stage ${ }^{111[}$. The researchers further required information about the women's husbands who entered the stage of menopause and what implications this had on them. It concluded to a number of results which included social, psychological and health effects of menopause. The most significant social effects of menopause included: a change occurred in the quality of the overall life (e.g., social disturbances, loneliness, absence of active role, and the distance from social and recreational activities). The psychological negative effects covered depression, anxiety, mood swings, insomnia and nervousness. The health effects comprised a number of symptoms like hot flushes, night sweats, osteoporosis, fatigue and general tiredness, decreased libido, concentration and memory problems, and other symptoms ${ }^{11[}$.

Santoro, et al. (2015) study offered several recommendations, the most important of which are: seeking the doctor or psychologist consultation and support to overcome the causes that may lead to disorders and help achieve psychological and social compatibility ${ }^{11[}$. The findings suggested that both spouses should take into account the psychological condition they both experience. The spouses experiencing menopause are advised to develop social networking instead of leaving oneself to social isolation and introversion which is assumed to help them achieve the psychological balance and increase their self-confidence. The spouses further are guided to continue giving others and participating actively in social gatherings that can assist them mingle with people. The results finally recommended conducting seminars to educate men and women about menopause stage and how to cope with its different effects ${ }^{11[}$.

Ibraheem, Oyewole and Olaseha (2015) investigated the experiences and perceptions of women in menopause, 
$85 \%$ of participants had never heard about menopause and the participants' major source of information was close relatives. The mean knowledge score for menopause was low with $2.8 \pm 1.0$. And only $28.0 \%$ of the participants could state at least one symptom of menopause. $54 \%$ who scored above the mean knowledge score had positive attitude towards menopause. $70 \%$ of participants had the certainty that sexual intercourse causes sickness for menopausal women. About 60.8\% of the participants believed that women should not tell anyone about their menopausal experiences. $83 \%$ had experienced at least one symptom out of the 19 common symptoms of menopause ${ }^{12}[\cdot$.Uncomfortable experiences attributed to menopause included dryness of the vagina, pain during intercourse, and joint pains. Actions that had been taken by participants included self-medication, and adoption of sexual abstinence ]12[.

Marahatta's (2012) study was designed to examine the major health problems in the females' mid-life, the age of menopause, frequency of menopausal symptoms, and what menopausal symptoms are common among Nepalese women. The results showed that the mean age of menopause found to be $49.9 \%$ with urinary tract infection being the major clinical diagnosis and physical menopausal symptoms being the commonest ${ }^{13[}$.

Another study done by Rodolpho, et al. (2016) explored men's perceptions and attitudes toward their wives in menopause $]^{7}[$. Four themes of experiences were categorized, such as: 1) misconceptions about overcoming menopause through coexistence and recognition of women's perspectives; 2) recognition of women's needs and efforts to provide support; 3) coping with changes in marital relations and need to start a new life; and 4) existence of several needs as husbands of women experiencing menopause $\mathrm{e}^{7[}$.

The researchers concluded that a better understanding of the changing experienced by menopausal women can foster the development of a better emotional support for wivesby husbands, which consequently improves the quality of marital interactions ${ }^{77[}$.To date worldwide, few surveys have targeted women's husbands to assess their perception of menopause, and they have been limited in scope. And in Jordan no studies targeted toward women's husbands therefore, the perception and attitudes of menopause shared by men are still mostly unknown; however, men may influence how their wives cope with and manage their menopausal transition period.
Objectives of the Study: This study is designed to examine men's perceptions and attitudes toward their wives who experience menopause in Jordan. And to explore the difference between men's perceptions and attitudes toward their wives who experience menopause and some of the demographic information.

\section{Research Questions:}

1. What is a level of men's perceptions and attitudes toward their wives who experience menopause in Jordan?

2. Is there a significant difference at level of (0.05) between men's perceptions and attitudes toward their wives who experience menopause in Jordan and some of the demographic information?

\section{Materials and Method}

This study used the descriptive approach to suit its purpose that deals with Men's perceptions and Attitudes toward their Wives Experiencing Menopause in Jordan. The study population consists of Men)their wives experiencing menopause in Jordan(. The sample size of (100) participants was estimated for this study using $G$ power analysis computer program developed by Faul and Erdfelder (1992), with a medium effect size 0.15, power of 0.8 , and $\alpha$ (the risk of Type I error) at $0.05^{14[\text {. }}$ Yet, 130 participants were selected to produce better power and more reliable findings and to compensate for uncompleted questionnaires.

Data Collection: The research was conducted after institutional review board approval at the university where the researchers work in. Research sample will be recruited from the private outpatients' gynecology clinics. Researchers explained the process of participation in the study and the need to read and approve the informed consent prior completing the designated questionnaires. Study participation was volunteered; the confidentiality and anonymity were assured.

Study tool (the questionnaire): The questionnaire used for the study is the Attitude towards Menopause (ATM) which developed by Neugarten et al (1963) and modified later in 2005 by Huffman et al. ${ }^{4[}[$-For this study the adoptedATM isforward and backward translated to Arabic ${ }^{15[\cdot}$. The goal of this method is that the two scales, the original and the one adapted for the new culture, will attain equivalence of meanings. The translated ATM consists of two sections, which are: 
Section One: Demographic Variables including: nationality, educational level, husband work, marital status, wife work, marry year, number of children, chronic disease, husband age, and wife age.

Section Two: Mean's Perceptions and Attitudes toward their Wives Experiencing Menopause in Jordan, it contains statements (1-19)

In order to verify the validity and reliability of Arabic version of the questionnaire, the researcher has distributed it to academic reviewers and other experts in the psychology field, to take their opinions, and rewording of some paragraphs, and make the required modifications to measure the content validity.

And to verity the reliability of the questionnaire, the researcher used the equation of internal consistency using Cronbach's alpha test for all statements of the survey, as the value of Cronbach's alpha was (0.824) and its higher than (0.60).

\section{The research type scale included two Likert scale as follows:}

- $\quad$ The Low degree from 1.00- 1.33.

- $\quad$ The Medium degree from $1.34-1.67$.

- The High degree from $1.68-2.00$.

Data Analysis: In order to answer the study questions which were formulated, a Statistical Package for Social Sciences (SPSS) (Version- 22) was used to analyze the collected data. The following statistical techniques and tests were used in data analysis:Frequencies and percentages to describe demographical variables. Conbach's Alpha reliability $(\alpha)$ to measure strength of the correlation and coherence between questionnaire items.Means and Standard Deviations. These techniques were used to illustrate respondent's level.Pearson Correlation test was used to illustrate the relationship between the variables.Independent Sample T-test, One Way ANOVA and LSD tests to measurement the study hypothesis.

\section{Results}

The researcher distributed (130) questionnaires to Men, (120) of which were retrieved, while (16) questionnaires were excluded from the analysis due to incomplete information, leading to (104) questionnaires valid for statistical analysis, showing the response rate of $(80 \%)$. (79.8\%) of the participants were Jordanian, (96\%) were below 50 years old. Majority of the participants' education was BSC with (35\%). Almost $(95 \%)$ of the participants were working. In addition, $(96 \%)$ were married. (74\%) of the participants were married for 20 years and above. Majority $(47 \%)$ had also 4-7 children. Of all participant only (41.3\%) hadwives with chronic diseases.

\section{Descriptive Analysis of Study Variables:}

Q1: What is a level of Men's Perceptions and Attitudes toward their Wives Experiencing Menopause in Jordan?

The researcher used the arithmetic mean, standard deviation, item importance and importance level to show the level of men's perceptions and attitudes toward their wives experiencing menopause in Jordan, as shown in Table (2).

Table (1): The level of Men's Perceptions and Attitudes toward their Wives Experiencing Menopause in Jordan in descending order.

\begin{tabular}{|c|l|c|c|c|c|c|}
\hline & Statements & Idea & Mean & $\begin{array}{c}\text { Std. } \\
\text { Deviation }\end{array}$ & Importance & $\begin{array}{c}\text { Importance } \\
\text { Level }\end{array}$ \\
\hline 1 & $\begin{array}{l}\text { A woman's body may change in menopause but } \\
\text { otherwise she doesn't change much. }\end{array}$ & Bod.Ch & 1.83 & 0.38 & 1 & High \\
\hline 2 & $\begin{array}{l}\text { A woman is concerned about how her husband } \\
\text { will feel about her after menopause. }\end{array}$ & Concern & 1.82 & 1.38 & 2 & High \\
\hline 3 & $\begin{array}{l}\text { Women should expect some troubles during } \\
\text { Menopause. }\end{array}$ & Trouble & 1.78 & 0.42 & 3 & High \\
\hline 4 & $\begin{array}{l}\text { Changes inside the body that women cannot } \\
\text { control cause all the trouble at menopause. }\end{array}$ & Uncont & 1.72 & 0.45 & 4 & High \\
\hline 5 & A woman should see a doctor at menopause. & See.Dr & 1.65 & 0.48 & 5 & Medium \\
\hline
\end{tabular}




\begin{tabular}{|c|c|c|c|c|c|c|}
\hline & Statements & Idea & Mean & $\begin{array}{l}\text { Std. } \\
\text { Deviation }\end{array}$ & Importance & $\begin{array}{l}\text { Importance } \\
\text { Level }\end{array}$ \\
\hline 6 & $\begin{array}{l}\text { The only difference between a woman who has } \\
\text { been through menopause and one who has not is } \\
\text { that one menstruates and the other doesn't }\end{array}$ & Menses & 1.64 & 0.48 & 6 & Medium \\
\hline 7 & Menopause is an unpleasant experience. & Unpleased & 1.63 & 0.49 & 7 & Medium \\
\hline 8 & $\begin{array}{l}\text { Menopause is one of the biggest changes that } \\
\text { happens in a woman's life. }\end{array}$ & Biggest & 1.61 & 0.53 & 8 & Medium \\
\hline 9 & $\begin{array}{l}\text { Menopause is a disturbing thing that women } \\
\text { generally dread. }\end{array}$ & Dread & 1.59 & 0.49 & 9 & Medium \\
\hline 10 & $\begin{array}{l}\text { Life is more interesting for a woman after } \\
\text { menopause. }\end{array}$ & Interest & 1.57 & 0.50 & 10 & Medium \\
\hline 11 & $\begin{array}{l}\text { Women usually feel "down in the dumps" at the } \\
\text { time of menopause. }\end{array}$ & Dump & 1.51 & 0.50 & 11 & Medium \\
\hline 12 & $\begin{array}{l}\text { Frankly speaking, just about every woman is } \\
\text { depressed about menopause. }\end{array}$ & Depress & 1.49 & 0.50 & 12 & Medium \\
\hline 13 & $\begin{array}{l}\text { Women are generally calmer and happier after } \\
\text { menopause. }\end{array}$ & Calm & 1.48 & 0.50 & 13 & Medium \\
\hline 14 & $\begin{array}{l}\text { A woman gets more confidence in herself after } \\
\text { menopause. }\end{array}$ & Confide & 1.45 & 0.50 & 14 & Medium \\
\hline 15 & $\begin{array}{l}\text { Going Through menopause really does not } \\
\text { change a woman in any important way. }\end{array}$ & Change & 1.44 & 0.50 & 15 & Medium \\
\hline 16 & $\begin{array}{l}\text { Women think of menopause as the beginning of } \\
\text { the end. }\end{array}$ & Beg. End & 1.36 & 0.48 & 16 & Medium \\
\hline 17 & $\begin{array}{l}\text { After menopause a woman feels freer to do } \\
\text { things for Herself. }\end{array}$ & Freedom & 1.34 & 0.47 & 17 & Medium \\
\hline 18 & $\begin{array}{l}\text { After menopause, women do not consider } \\
\text { themselves "real women" }\end{array}$ & Real & 1.31 & 0.46 & 18 & Low \\
\hline \multirow[t]{2}{*}{19} & Women generally feel better after menopause. & Feel & 1.30 & 0.46 & 19 & Low \\
\hline & Total & & 1.55 & 0.16 & & Medium \\
\hline
\end{tabular}

As shown in Table (1) that the means values of (Men's Perceptions and Attitudes toward their Wives Experiencing Menopause in Jordan), ranged from (1.831.30), where the whole dimension scored a total mean of (1.55), which is of a medium level. (A woman's body may change in menopause but otherwise she doesn't change much) ranked first with a mean of (1.83), and standard deviation of (0.38), which is of a high level, and (A woman is concerned about how her husband will feel about her after menopause) ranked second with a mean of (1.82) and standard deviation of (1.38), which is of a high level. (Women generally feel better after menopause) ranked last with a mean of (1.30), and standard deviation of (0.46), which is of a low level.

Q2: Is there significant relationship at level of (0.05) between Men's Perceptions and Attitudes toward their Wives Experiencing Menopause in Jordan and some of the demographic information?

The study used Pearson Correlation test to illustrate the relationship between Men's Perceptions and Attitudes and some of the demographic information as shown in table (2). 
Table (2) Pearson Correlation test

\begin{tabular}{|l|l|c|c|c|c|c|}
\hline & & Age & Nationality & Education & Marry & No. Child \\
\hline \multirow{2}{*}{$\begin{array}{l}\text { Men's Perceptions and } \\
\begin{array}{l}\text { Attitudes toward their Wives } \\
\text { Experiencing Menopause }\end{array}\end{array}$} & Pearson Correlation & -.137 & -.036 & -.094 & .074 & $.329^{* *}$ \\
\cline { 2 - 8 } & Sig. (2-tailed) & .166 & .714 & .342 & .458 & .001 \\
\cline { 2 - 8 } & $\mathrm{N}$ & 104 & 104 & 104 & 104 & 104 \\
\hline
\end{tabular}

Table (2) showed that there is no relationship at level of (0.05) between the mean score of men's perceptions and attitudes toward their wives experiencing menopause and the mean scores of age, nationality, educational level and marry year. Pearson Correlation values were (-0.137, $-0.036,-0.094$ and 0.074$)$ and it's not significant at level of (0.05). On the other hand, the results showed that there is a positive relationship between men's perceptions and attitudes and number of children, Pearson Correlation value was (0.329) andit'ssignificant at level of (0.01).

\section{Study hypotheses test:}

H0: There are no statistically significant differences in the men's perceptions and attitudes toward their wives experiencing menopause in Jordan according to the age, nationality, educational level, and marry year.

Age: The study used Independent Sample T-test to identify the statistically significant differences in the men's perceptions and attitudes toward their wives experiencing menopause in Jordan according to the age as shown in table (3).

Table (3) Independent Sample T-test

\begin{tabular}{|l|c|c|c|c|c|c|c|}
\hline Source & Age & N & Mean & Standard deviation & T value & df & Sig. \\
\hline \multirow{2}{*}{$\begin{array}{l}\text { Men's Perceptions and Attitudes toward } \\
\text { their Wives Experiencing Menopause }\end{array}$} & $50-60$ & 77 & 1.57 & .16 & \multirow{2}{*}{1.394} & \multirow{2}{*}{102} & \multirow{2}{*}{.166} \\
\cline { 2 - 8 } & $61-70$ & 27 & 1.52 & .13 & & \\
\hline
\end{tabular}

*Significance at level of (0.05)

The results showed that there are no statistically significant differences in the Men's Perceptions and Attitudes according to the age in Jordan, mean value for (50-60) category was of (1.57) with standard deviation of (0.16) "medium level", and mean value for (61-70) category was of (1.52) with standard deviation of (0.13) "medium level", $(\mathrm{t})$ value $=(1.394)$ and the variance between means values not significant at level of $(0.05)$.

Nationality: The study used Independent Sample T-test to identify the statistically significant differences in in the men's perceptions and attitudes toward their wives according to the nationality as shown in table (4). The results showed that there are no statistically significant differences in the men's perceptions and attitudes according to the nationality in Jordan, mean value for (Jordanian) category was of (1.56) with standard deviation of (0.16) "medium level", and mean value for (Non-Jordanian) category was of (1.54) with standard deviation of (0.16) "medium level" also, $(t)$ value $=(0.367)$ and the variance between means values not significant at level of $(0.05)$.

Table (4) Independent Sample T-test

\begin{tabular}{|l|l|c|c|c|c|c|c|}
\hline Source & Nationality & N & Mean & Standard deviation & T value & df & Sig. \\
\hline \multirow{2}{*}{$\begin{array}{l}\text { Men's Perceptions and Attitudes toward } \\
\text { their Wives Experiencing Menopause }\end{array}$} & Jordanian & 83 & 1.56 & .16 & \multirow{2}{*}{0.367} & \multirow{2}{*}{102} & \multirow{2}{*}{.714} \\
\cline { 2 - 5 } & Non-Jordanian & 21 & 1.54 & .16 & \\
\hline
\end{tabular}

*Significance at level of (0.05) 
Marry Year: The study used One Way ANOVA test to identify the statistically significant differences in the men's perceptions and attitudes according to the marry year as shown in table (5):

\section{Table (5) One Way ANOVA test}

\begin{tabular}{|l|c|c|c|c|c|}
\hline & Sum of Squares & df & Mean Square & F & Sig. \\
\hline Between Groups & 0.218 & 2 & 0.109 & 4.744 & $0.011^{*}$ \\
\hline Within Groups & 2.32 & 101 & 0.023 & & \\
\hline Total & $\mathbf{2 . 5 3 7}$ & $\mathbf{1 0 3}$ & & & \\
\hline
\end{tabular}

*Significant at level of $(0.05)$

The results showed that there are statistically significant differences in the men's perceptions and attitudes according to the marry year; least significant difference (LSD-post hoc) test for multiple comparisons was used to illustrate the source of variance as shown in table (6).

Table (6) LSD test

\begin{tabular}{|c|c|c|c|c|c|c|}
\hline \multirow{2}{*}{ (I) Marry } & \multirow{2}{*}{$(J)$ Marry } & \multirow{2}{*}{ Difference (I-J) } & \multicolumn{2}{|c|}{ Mean Interval } & \multicolumn{3}{|c|}{$95 \%$ confidence } \\
\cline { 4 - 7 } & & & Std. Error & Sig. & Lower Bound & Upper Bound \\
\hline \multirow{2}{*}{$1-10$} & $10-20$ & $.14561^{*}$ & .05869 & .015 & .0292 & .2620 \\
& $>20$ & .01902 & .04703 & .687 & -.0743 & -.2620 \\
\hline \multirow{2}{*}{$10-20$} & $1-10$ & $-.14561^{*}$ & .05869 & .015 & -.2114 & -.0292 \\
& $>20$ & $-.12659^{*}$ & .04277 & .004 & -.1123 & .0417 \\
\hline \multirow{2}{*}{$>20$} & $1-10$ & -.01902 & .04703 & .687 & .0417 & .2114 \\
\hline
\end{tabular}

*The mean difference is significant at the 0.05 level.

LSD test result in table (6) showed that the variance in the men's perceptions and attitudes was in favor of marry year category (1-10 year) then the variance was in favor of ( $>20$ year).

\section{Discussion}

This study aims to explore the perceptions and attitudes of men towards their wives during menopause in Jordan. The study found that the men's perception and attitudewas medium in level with a mean of (1.55). Many studies revealed that men were aware and understand of their partner's menopausal transition ${ }^{] 10[}$ and showeda positive and medium level of perception towardmenopause $^{16,}$ 17[. Nevertheless, Erbil (2018) study which showed negative perception toward menopause]18[, in addition to other many studies ]19[. A woman's body may change in menopause but otherwise she doesn't change much which ranked as the highest in importance may due to men'swives negative perception of menopause, and generally the women's thoughts about body image and how much it is important for her to stay attractive for her husband so he will be satisfied in his marriage, and this can be assured by the second highest ranked item which is a woman is concerned about how her husband will feel about her after menopause.in addition, many women according to their culture and raising process they think about what other people feel about her forgetting her self-satisfaction and her feel about herself. This isconsistent with other studies ${ }^{20[}$.women generally feel better after menopause, which considered less important to men and this can be explained by previous paragraph and support the women thought about their husbands feelings and perception toward menopause. Also the constructivist view of the learning process assumes that the individuals build their own knowledge on the base of the knowledge they already have, and therefore, see the world in ways that are acceptable and useful to them from their point of view. In building process of this knowledge, influenced by previous social and scientific experiences, individuals begin to form different types of beliefs that appear in the form of alternative perceptions of some real concepts. 
Each cognitive activity is designed to explore, activate the perceptions stored in memory. Through a content that depicts the man in the menopause, the man looks at the mirror according to his social and cognitive perceptions, results of this study is consistent with study of Rodolpho, et al. (2016) $]^{7 \text { [. }}$

There is no relationship noticed between men's perceptions and attitudes toward their wives experiencing menopause in Jordan and age, nationality, educational level, and marry year.Same results showed by Parish, et al. ]10[except for educational level which was positively correlated to men's perception of menopause. On the other hand, the results showed that there is a positive relationship between men's perceptions and attitudes and number of children. This result was consistent with other studies ]21[. This study result may due to increase males' involvement in family matters and health concern when they have more children since they have to help the mothers in caring of children and decision making. In Arab culture the males are considered the gatekeeper for all important decisions related to family health and they have a direct effect on their wives and children health. Also the bond between husband and wife increase with the number of children so this will lead to increase male involvement.

The results showed that there are no statistically significant differences in the men's perceptions and attitudes toward their wives experiencing menopause in Jordan according to the age, and nationality in Jordan. While, there are statistically significant differences in the men's perceptions and attitudes toward their wives experiencing menopause in Jordan according to the marry year in favor of 1-10-year category. This result is logical because when two marrying couple spend more years to gather they will develop more acceptance and understanding to each other physiological and psychological wellbeing, also sense of support to each other will increased.

Limitations of the study: The findings of the current study should be generalized with caution due to the following limitations: the study focuses only on men's perceptions and attitudes toward their wives, and geographical limitation.

\section{Conclusion}

This analysis described men's perception and attitude of their wives menopause. Men are aware of changes experienced by their wives during their menopause. To create a more positive attitude towards menopause, men need positive information from health professionals. Advising men to engage in various activities with his wife during menopause can positively affect their attitudes, improve their body image. Further research needed about the role of women's husband in easing the menopause transition period for their wives and how they can support them in this period.

Ethical Clearance: Ethical Approval was taken from the Ethical committee in the university where the researchers work in, and the administrative department in the private clinics where the participants were recruited.

Conflict of Interest: The authors declare no conflicts of interest.

Source of Funding: This research received no specific grant from any funding agency, commercial entity, or not-for-profit organization.

\section{References}

1. Hammar M, Berg G, Fahraeus L, Larsson-Cohn U. Climacteric symptoms in an unselected sample of Swedish women. Maturitas.,1984. 6(4), 345-350.

2 . Shea, Jeanne. Chinese women's symptoms: Relation to menopause, age and related attitudes. Climacteric: the journal of the International Menopause Society. 2006. 9. 30-9. 10.1080/13697130500499914.

3. Bride MB, Rhodes DJ, Shuster LT. Vulvovaginal atrophy. Mayo Clin Proc,2010. 85, 87-94.

4. Hoffmann M, Hammar M, Kjellgren KI, LindhAstrand L, Brynhildsen J. Changes in women's attitudes towards and use of hormone therapy after HERS and WHI. Maturitas, 2005. 52(1), 11-17.

5. Kingsberg S, Krychman M, Graham S, Bernick B, Mirkin S. The Women's EMPOWER Survey: identifying women's perceptions on vulvar and vaginal atrophy (VVA) and its treatment. J Sex Med,2017. 14, 413-424

6. Agwu, U.M., Umeora, O.U.j. and Ejikeme, B.N. Pattern of menopausal symptoms and Adaptive ability in a rural population in Southeast Nigeria. Journal of Obstetrics and Gynaecology, 2008. 28(2), 217-21.

7. Rodolpho JR, Cid Quirino B, Komura Hoga LA, Lima Ferreira Santa Rosa P. Men's perceptions and attitudes toward their wives experiencing menopause, J Women Aging, 2016. 28(4), 322-33 
8. Jaber,R., Khalifeh,S., Bunni,F., \& Diriye,M. Patterns and severity of menopausal symptoms among Jordanian women. J Women Aging, 2017. 29(5), 428-436.

9. Birkhaeuser M, Genazzani A. Pre-Menopause, Menopause and Beyond, 2018. Vol 5: Frontiers in Gynecological Endocrinology, Springer International Publishing AG, Cham, Switzerland.

10. Parish, S. J., Faubion, S. S., Weinberg, M., Bernick, B., \& Mirkin, S. The MATE survey: men's perceptions and attitudes towards menopause and their role in partners' menopausal transition. Menopause (New York, N.Y.), 2019. 26(10), 1110-1116. https://doi.org/10.1097/ GME.0000000000001373.

11. Santoro, N., Epperson, C. N., \& Mathews, S. B. Menopausal Symptoms and Their Management. Endocrinology and metabolism clinics of North America, 2015. 44(3), 497-515. https://doi. org/10.1016/j.ecl.2015.05.001

12. Ibraheem O.M, Oyewole O.E and Olaseha I.O. Experiences and Perceptions of Menopause among women in Ibadan South East Local Government area, Nigeria, Afr. J. Biomed. 2015. 18, 81 - 94.

13. Marahatta RK. Study of menopausal symptoms among peri and postmenopausal women attending NMCTH. Nepal Med Coll J. 2012. 14(3), 251255.

14. Faul, F., \& Eedeeldee, E. GPOWER: A priori-, post hoc-, and compromise power analyses for MSDOS [Computer program]. 1992.Bonn, Germany: Bonn University.
15. López-Campos, J.L., Failde, I., León, A., Masa, F., Barrot, E., Benítez, J.M., et al. Calidad de vidarelacionadaconlasalud depacientesenprograma de ventilaciónmecánicadomiciliaria. La versiónespañola del cuestionario SRI. 2006.

16. Çoban A, Nehir S, Demirci H, Özba. menopausal symptoms of marital adjustment and attitude toward menopausal of married women in the climacteric period. FÜ Sag ` Bil T, 2008.22, 343-349

17. Akkuzu G, Orsal O, Kecialan R. Women's attitudes towards the menopause andthe influencing factors. TurkiyeKlinikleri J Med Sci.2009, 29, 666-674.

18. Erbil, N. Attitude towordmenoupose and depression,body image of womenduringmenoupose. Alexandria journal of medicine.2018.54. 241246. http://dx.doi.org/10.1016/j.ajme.2017.05.012 2090-5068/

19. Liu J, Eden J. Experience and attitudes toward menopause in Chinese womenliving in Sydney-a cross sectional survey. Maturitas.2007, 58, 359365

20. Banister EM. Women's midlife confusion: "Why am I feeling this way? Health Nurs.2000, 21, 745764

21. Del sueldo, M., Martell-claros N., abad-cardie, M., Zilberman, J., Marchegiani, R., FernándezPérez, C. Health perception in menopausal women. International Journal of Women's Health, 2018. 10, 655-661. 